\title{
Effect of Pantograph's Main Structure on the Contact Quality in High-Speed Railway
}

\author{
Jiangwen Wang $(\mathbb{D}$ and Guiming Mei $(\mathbb{C}$ \\ State Key Laboratory of Traction Power, Southwest Jiaotong University, Chengdu, China \\ Correspondence should be addressed to Guiming Mei; 13880068468@163.com
}

Received 15 May 2021; Revised 5 July 2021; Accepted 22 July 2021; Published 5 August 2021

Academic Editor: Francisco Beltran-Carbajal

Copyright (c) 2021 Jiangwen Wang and Guiming Mei. This is an open access article distributed under the Creative Commons Attribution License, which permits unrestricted use, distribution, and reproduction in any medium, provided the original work is properly cited.

\begin{abstract}
In general, the electrical energy is provided to the high-speed train through the pantograph-catenary sliding contact. The variation of the dynamic contact force is expected to be small enough to keep the good current collection quality and to extend the service life of the pantograph-catenary system. In this paper, the two tension wires of the catenary are discretized by the sine-series expansions, a multibody dynamics theory based on relative coordinates is adopted to describe the dynamic behavior of the pantograph, and the standard deviation (STD) of dynamic contact force is used as the indicator to evaluate the contact quality. The objective is to investigate how the variations of the pantograph's main structure influence the contact quality, which may support the structural design and parameter optimization of the pantograph in high-speed railway.
\end{abstract}

\section{Introduction}

The pantograph-catenary system (PCS) is the key subsystem of high-speed railway, shown in Figure 1, which transmits the electrical energy from the traction substations to the moving high-speed trains. The catenary is arranged above the track centerline, and the pantograph is mounted on the roof of the train, forming the special sliding-contact-current-collection system in high-speed railway. The contact quality must be strictly required, which means that the dynamic contact force should not be too large or too small to avoid the impact or arc damage [1].

To evaluate the contact quality, lots of methods have been developed to describe the interaction of the PCS [2-18]. Besides, the aerodynamic effect [19-23], the vibration caused by track or contact wire irregularity [24-26], and the technology of active control pantograph [27-33] have been intensively studied to illustrate the PCS.

In the research field of parameters optimization of the PCS, Park et al. [33] gave a pantograph with improved parameters based on the linear spring-mass model suiting for the high-speed rail vehicle. Kim et al. [34] investigated the sensitivity of the PCS, confirming that the span length and the plunger spring constant are the two important design variables of the PCS. Zhou and Zhang [35] pointed out that the stiffness and damping of the pan-head and frame, the static lifted force, and the tension force of the contact wire have a significant influence on the dynamic performance of the PCS. Ambrósio et al. [36] redesigned the suspension characteristics of the pantograph head to improve the contact quality. Pombo and Ambrósio [37] studied the influence of the head mass, the head suspension stiffness, and the damper coefficient, indicating that the increase in the pantograph head suspension stiffness and lower damper will improve the stability of the contact interaction and decrease the potential for contact loss. Lee et al. [38] applied the response surface analysis method and the differential evolutionary algorithm to improve the current collection performance. Massat et al.[39] compared the differences between current mechanical suspension and pneumatic device with associated nonlinear stiffness of pantograph, pointing out that the impact of pneumatic suspension will decrease compared with the case of the lumped mass model.

However, most research works mentioned above adopt the lumped mass model to handle the parameters optimization problems of the pantograph, shown in Figure 2, and 


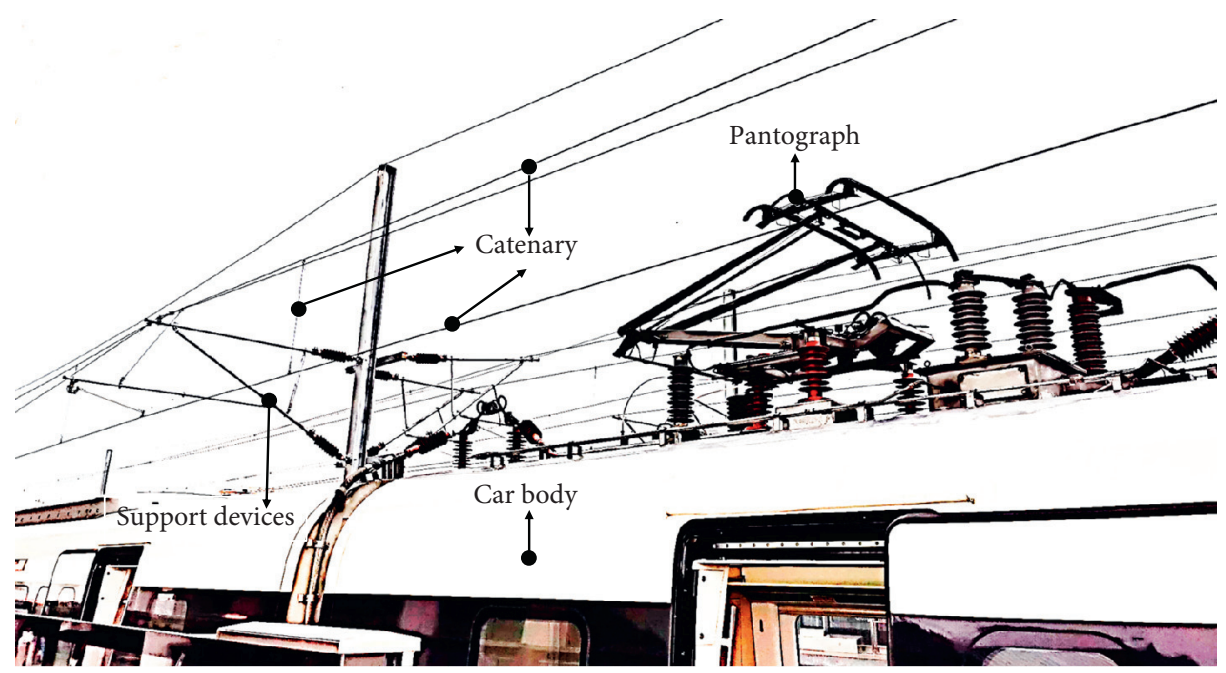

Figure 1: Pantograph-catenary systems.

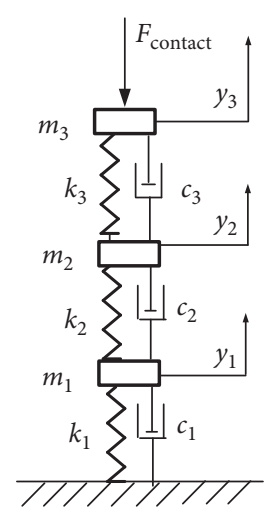

Figure 2: Typical linear spring-mass model of the pantograph.

the meanings of the physical quantity are shown in reference [34], which did not concern the geometric of the pantograph's main frame; thus, it is not clear enough how the variation of the pantograph's main frame influences the dynamic contact quality.

The objective is to evaluate the variation of the pantograph's main frame to contact quality, focusing on the geometric parameters of the main frame. The multibody model of the pantograph based on relative coordinates theory [40-44] is developed to describe the variation of main frame. The dynamic vertical displacements of the two tension wires in the catenary are described by the Fourier sineseries expansions, respectively, and all general load vectors are acquired and solved in each time step directly. The paper is organized as follows:

(a) In Section 2, the multibody dynamic model of the pantograph is established and the dynamic equations of the catenary are built

(b) In Section 3, the initialization strategy of the catenary is given in detail and validated compared with the reference (c) In Section 4, the variation of the pantograph's main frame and the research conditions are described carefully

(d) In Section 5, the simulation results are given and the main conclusions are summed about how the main structure affects the contact quality

\section{Methodology}

2.1. Modeling of the Pantograph. The single-arm type pantograph object is simplified, keeping the main load-carrying components stay, including the base frame, the link, the lower frame, the upper frame, the supporting rack, the front contact strip, and the rear contact strip, shown in Figure 3.

Based on the relative coordinates theory in multirigid body dynamics [40-44], the relationship between the main components is described in Figure 4, and the meanings of the symbols are shown in Table 1.

The relationship of the pantograph's main structure based on the graph theory is shown in Figure 5, and $\mathrm{O}_{5}$ is the cut-off hinge through which the nontree shape mechanical system is transferred to a tree shape system. The relation matrix of the main frame is

$$
c_{i j}=\left[\begin{array}{lllll}
c_{11} c_{12} & & & & \\
& c_{22} c_{23} & & \\
& & c_{33} & \\
& & & c_{44}
\end{array}\right] .
$$

The dynamic equation of the pantograph's main structure according to the theory by Roberson and Wittenburg [41-44] is

$$
A \ddot{q}=B,
$$

in which the expressions of $A$ and $B$ are 


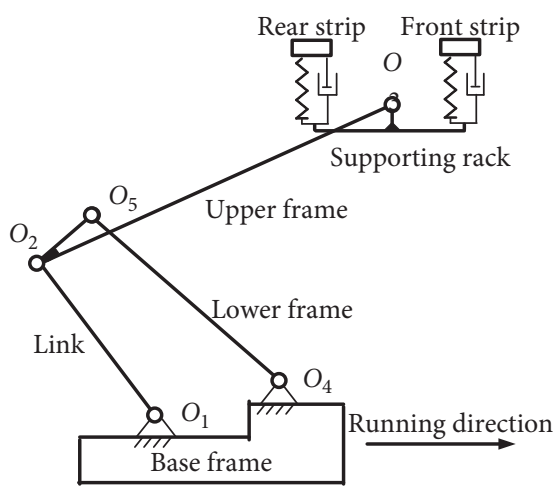

FIGURE 3: Main load-carrying components of the single-arm type pantograph.

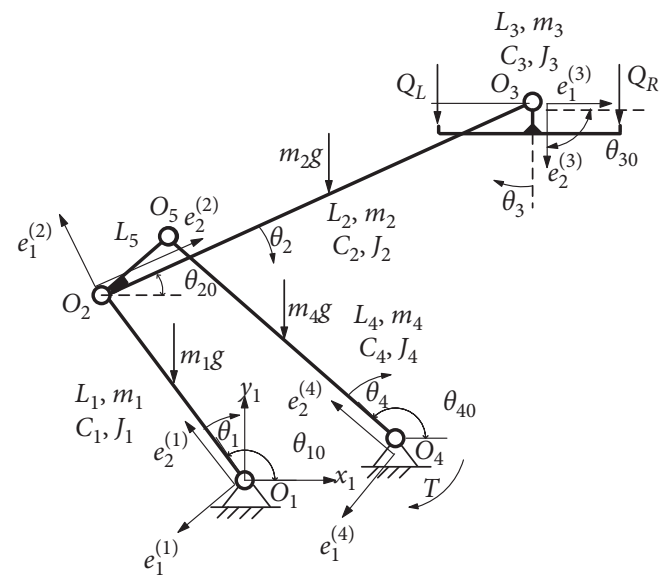

FIGURE 4: Relationship of the main frame based on relative coordinates theory.

$$
\begin{aligned}
& A=\alpha^{T} \cdot m \alpha+\beta^{T} \cdot m \beta, \\
& \left.B=\alpha^{T} \cdot\left(F^{g}-m u\right)+\beta^{T} \cdot\left(M^{g}-J \cdot \sigma-\varepsilon\right)+p \cdot M^{a}\right),
\end{aligned}
$$

where $A$ is the generalized mass matrix of the frame structure, $B$ is the generalized load vector, $q$ is the relative coordinates of the frame structure, $\alpha$ and $\beta$ are the transfer matrix, $m$ and $J$ are the mass matrix and inertia matrix of the system, $F^{g}$ is the external force vector, $M^{g}$ is the external moment vector to the mass center of the system, $M^{a}$ is the external moment vector of the internal rigid body of each hinge point to the external rigid body, $u, \sigma$, and $\varepsilon$ are the transfer vectors, and $p$ is the coordinate matrix of the revolutions.

To describe the constraint equation, the related parameters and structure are shown in Figure 6.

$L_{a}$ and $L_{b}$ are the distance between $O_{1}$ and $O_{4}$ in $x_{1}$ and $y_{1}$ direction separately. The constraint equation of the main frame is

$$
\Phi(q, t)=0
$$

TABle 1: The physical meaning of the symbols in Figure 4.

\begin{tabular}{lc}
\hline Symbols & Physical meaning \\
\hline$O_{1}, x_{1}, y_{1}$ & Global coordinate system \\
$O_{1}, O_{2}, O_{3}, O_{4}, O_{5}$ & Hinge points \\
$e_{1}^{(1)}, e_{2}^{(1)}, e_{3}^{(1)}$ & Local coordinate fixed on link \\
$e_{1}^{(2)}, e_{2}^{(2)}, e_{3}^{(2)}$ & Local coordinate fixed on upper frame \\
$e_{1}^{(3)}, e_{2}^{(3)}, e_{3}^{(3)}$ & Local coordinate fixed on supporting rack \\
$e_{1}^{(4)}, e_{2}^{(4)}, e_{3}^{(4)}$ & Local coordinate fixed on lower frame \\
$L_{1}, L_{2}, L_{3}, L_{4}$ & Length \\
$C_{1}, C_{2}, C_{3}, C_{4}$ & Center of mass \\
$m_{1}, m_{2}, m_{3}, m_{4}$ & Mass \\
$J_{1}, J_{2}, J_{3}, J_{4}$ & Moment of inertia around the center of mass \\
$\theta_{10}, \theta_{20}, \theta_{30}, \theta_{40}$, & Initial angle \\
$\theta_{1}, \theta_{2}, \theta_{3}, \theta_{4}$ & Relative motion angle \\
$L_{5}$ & The length between $O_{2}$ and $O_{5}$ \\
$T$ & Raise torque \\
$Q_{L}, Q_{R}$ & Left and right forces action on supporting \\
$g$ & rack \\
\hline
\end{tabular}

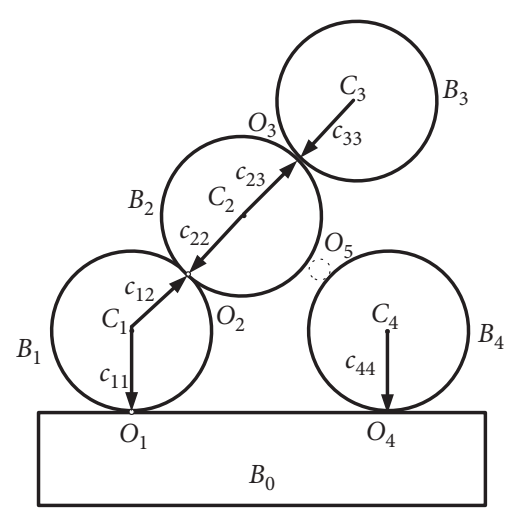

FIGURE 5: Description of pantograph's main structure based on the graph theory.

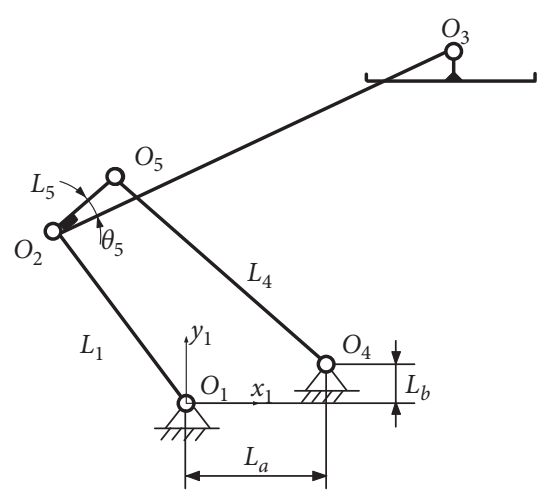

FIgURE 6: Simplified graph from Figure 4 to describe the constraint equation.

Then, the dynamic model of the pantograph's main structure is established combining the Lagrange multiplier $\lambda$ item.

$$
A \ddot{q}=B+\Phi^{T} \lambda
$$




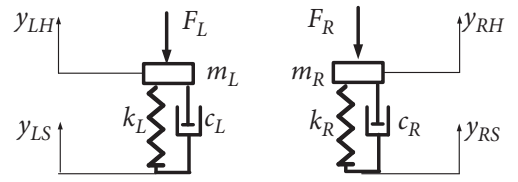

FIGURE 7: Left and right collector strip of the pantograph.

For modeling of pantograph head, each collector strip is simplified as a single spring-mass model, shown in Figure 7.

The differential equations of collector strips are

$$
\begin{aligned}
m_{L} \ddot{y}_{L H} & =b_{L}, m_{R} \ddot{y}_{R H}=b_{R}, b_{L} \\
& =k_{L}\left(y_{L S}-y_{L H}\right)+c_{L}\left(\dot{y}_{L S}-\dot{y}_{L D}\right)-F_{L}, b_{R} \\
& =k_{R}\left(y_{R S}-y_{R H}\right)+c_{R}\left(\dot{y}_{R S}-\dot{y}_{R D}\right)-F_{R} .
\end{aligned}
$$

Finally, the dynamic equation of the pantograph is assembled as follows:

$$
\left[\begin{array}{lll}
A & & \\
& m_{L} & \\
& & m_{R}
\end{array}\right]\left\{\ddot{q}_{y_{L H}} \ddot{y}_{R H}\right\}=\left\{\begin{array}{c}
B+\Phi_{q}^{T} \lambda \\
b_{L} \\
\\
\end{array}\right.
$$

\subsection{Modeling of Catenary}

2.2.1. Basic Matrix. The simple catenary is mainly composed of the contact wire, the messenger wire, the droppers, and the support devices. The supports of the messenger wire and the steady arms are equivalent to the springs connected to the fixed points, shown in Figure 8. To describe the nonlinear behaviors of the droppers while compressing, the droppers are replaced by the spring with only tension stiffness, whose mass is added on the connecting points of each wire.

The dynamic displacement of each wire can be described by Fourier sine-series expansions [45].

$$
\begin{aligned}
& y_{M}(x, t)=\sum_{m=1}^{m_{0}} A_{m}(t) \sin \left(\frac{m \pi x}{L}\right), \\
& y_{C}(x, t)=\sum_{n=1}^{n_{0}} A_{n}(t) \sin \left(\frac{n \pi x}{L}\right),
\end{aligned}
$$

where $y_{M}$ and $y_{C}$ represent the dynamic displacement of the messenger wire and the contact wire separately, $m_{0}$ and $n_{0}$ are the maximum expansion orders, $L$ is the total length of the catenary, $A_{m}$ and $A_{n}$ are the amplitudes of the $m$ th sine term and the $n$th sine term, $x$ is the distance along the catenary, and $t$ is the time.
To establish the equation of the catenary, the second Lagrange equation is adopted:

$$
\begin{gathered}
\frac{\mathrm{d}}{\mathrm{d} t}\left(\frac{\partial L_{M}}{\partial \dot{A}_{m}}\right)-\frac{\partial L_{M}}{\partial A_{m}}=Q_{A_{m}} \\
\frac{\mathrm{d}}{\mathrm{d} t}\left(\frac{\partial L_{C}}{\partial \dot{A}_{n}}\right)-\frac{\partial L_{C}}{\partial A_{n}}=Q_{A_{n}}, \\
L_{M}=T_{M}-V_{M}, \\
L_{C}=T_{C}-V_{C} .
\end{gathered}
$$

$T_{M}$ and $T_{N}$ are the kinetic energy of each wire, $V_{M}$ and $V_{N}$ are the potential energy, and $Q_{A m}$ and $Q_{A n}$ are the $m$ th and $n$th general load of each wire, where

$$
\begin{aligned}
& T_{M}=\frac{1}{2} \int_{0}^{L} \rho_{M} \dot{y}^{2}{ }_{M} \mathrm{~d} x+\frac{1}{2} \sum_{i=1}^{n_{D}} m_{M i} \dot{y}_{M}^{2}\left(x_{i}, t\right) \\
& V_{M}=\frac{1}{2} F_{M W} \int_{0}^{L}\left(\frac{\partial y_{M}}{\partial x}\right)^{2} \mathrm{~d} x+\frac{1}{2} E_{M} I_{M} \int_{0}^{L}\left(\frac{\partial^{2} y_{M}}{\partial x^{2}}\right)^{2} \mathrm{~d} x \\
& T_{C}=\frac{1}{2} \int_{0}^{L} \rho_{C} \dot{y}_{C}^{2} \mathrm{~d} x+\frac{1}{2} \sum_{i=1}^{n_{D}} m_{C i} \dot{y}_{C}{ }_{C}\left(x_{i}\right) \\
& V_{C}=\frac{1}{2} F_{C W} \int_{0}^{L}\left(\frac{\partial y_{C}}{\partial x}\right)^{2} \mathrm{~d} x+\frac{1}{2} E_{C} I_{C} \int_{0}^{L}\left(\frac{\partial^{2} y_{C}}{\partial x^{2}}\right)^{2} \mathrm{~d} x
\end{aligned}
$$

$\rho_{M}$ and $\rho_{C}$ are the line density of each wire, $m_{M i}$ and $m_{C i}$ are the mass of $i$ th dropper added on each wire, $n_{D}$ is the dropper number, $F_{M W}$ and $F_{C W}$ are the tension forces of each wire, $E_{M}$ and $E_{C}$ are the elastic modulus, and $I_{M}$ and $I_{C}$ are the moments of inertia of each wire.

Combining equations (14)-(16), the catenary system in the coordinate spaces $\left\{A_{m}\right\}$ and $\left\{A_{n}\right\}$ is written as follows:

$$
\left[\begin{array}{cc}
M_{M} & \\
& M_{C}
\end{array}\right]\left(\ddot{A}_{M} \ddot{A}_{C}\right)+\left[\begin{array}{cc}
C_{M} & \\
& C_{C}
\end{array}\right]\left(\begin{array}{c}
\dot{A}_{M} \\
\dot{A}_{C}
\end{array}\right)+\left[\begin{array}{cc}
K_{M} & \\
& K_{C}
\end{array}\right]\left(\begin{array}{c}
A_{M} \\
A_{C}
\end{array}\right)=\left(\begin{array}{c}
Q_{A M} \\
Q_{A C}
\end{array}\right)
$$

$M_{M}, M_{C}, K_{M}$, and $K_{C}$ are the mass matrix and stiffness matrix of each wire which are expressed by 


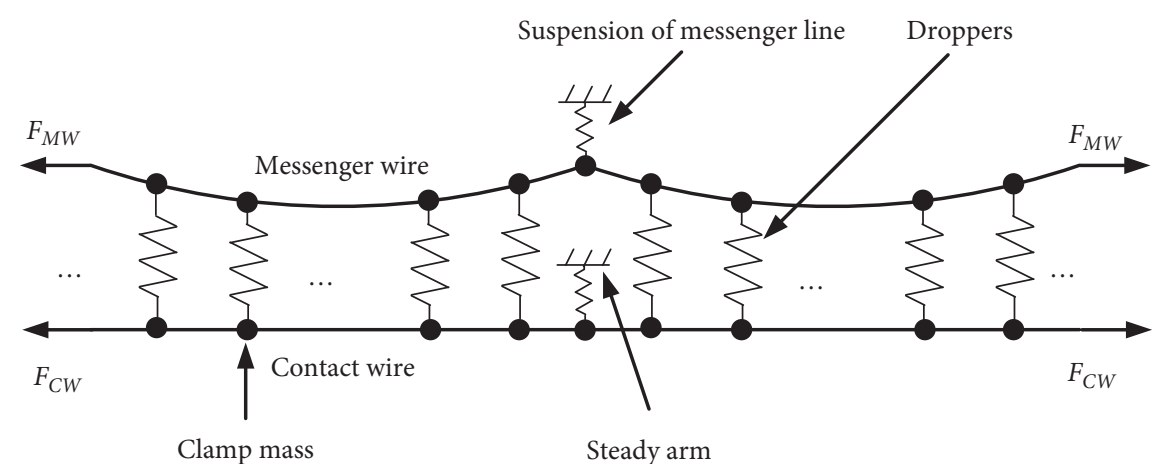

Figure 8: Model of catenary.

$$
\begin{gathered}
M_{M}=M_{M}^{(1)}+M_{M}^{(2)}, \\
M_{M}^{(1)}(i, k)=\sum_{j=1}^{n_{D}} m_{M D j} \sin \left(\frac{i \pi x_{D j}}{L}\right) \sin \left(\frac{k \pi x_{D j}}{L}\right) \\
+\sum_{j=1}^{n_{S}} m_{M S j} \sin \left(\frac{i \pi x_{S j}}{L}\right) \sin \left(\frac{k \pi x_{S j}}{L}\right), \\
M_{M}^{(2)}(i, i)=\frac{\rho_{M} L}{2}, \\
K_{M}(i, i)=\frac{F_{M W} \pi^{2} i^{2}}{2 L}+\frac{E_{M} I_{M} \pi^{4} i^{4}}{2 L^{3}}, \\
M_{C}^{(1)}(i, k)=\sum_{j=1}^{n_{D}} m_{M C j} \sin \left(\frac{i \pi x_{D j}}{L}\right) \sin \left(\frac{k \pi x_{D j}}{L}\right) \\
+\sum_{j=1}^{n_{S}} m_{C S j} \sin \left(\frac{i \pi x_{S j}}{L}\right) \sin \left(\frac{k \pi x_{S j}}{L}\right), \\
M_{C}^{(2)}(i, i)=\frac{\rho_{C} L}{2}, \\
K_{C}(i, i)=\frac{F_{C W} \pi^{2} i^{2}}{2 L}+\frac{E_{C} I_{C} \pi^{4} i^{4}}{2 L^{3}} .
\end{gathered}
$$

2.2.2. Load Vector. $Q_{A M}$ is composed of $Q_{A m}$, and $Q_{A C}$ is composed of $Q_{A n}$, which is the generalized load vector in coordinate spaces $\left\{A_{m}\right\}$ and $\left\{A_{n}\right\}$. The concentrated forces $F_{i}$ $\left(N_{F}\right.$ is the number of $\left.F_{i}\right)$ and the distributed forces $\bar{f}(x)$ can be transferred by

$$
\begin{aligned}
Q_{k 1} & =\sum_{i=1}^{N_{F}} F_{i} \frac{\partial y_{i}}{\partial q_{k 1}} ; \\
Q_{k 2} & =\frac{\partial\left(\int_{0}^{L} \bar{f}(x) y(x, t) \mathrm{d} x\right)}{\partial q_{k 2}} .
\end{aligned}
$$

For the messenger wire, the distributed force is $-\rho_{M} g$, and the concentrated forces consist of the dropper forces $-F_{D k}$ and the supporting forces of messenger wire $F_{S M k}$. The general load expression $\left\{Q_{A_{m}}\right\}$ can be transferred by

$$
Q_{A_{m}}=\frac{\partial\left(\int_{0}^{L}-\rho_{M} g y_{M}(x, t) \mathrm{d} x\right)}{\partial A_{m}}+\sum_{k=1}^{n_{D}} \frac{\partial\left(-F_{D k} y_{M}\left(x_{D k}, t\right)\right)}{\partial A_{m}}+\sum_{k=1}^{n_{S}} \frac{\partial\left(F_{S M k} y_{M}\left(x_{S k}, t\right)\right)}{\partial A_{m}} .
$$

For the contact wire, the distributed force is $-\rho_{C} g$, and the concentrated forces consist of the dropper forces $F_{D k}$, the supporting forces of messenger wire $F_{S C k}$, and the dynamic contact force $F_{C}$. The general load expression $\left\{Q_{A_{n}}\right\}$ can be transferred by 


$$
Q_{A_{n}}=\frac{\partial \int_{0}^{L}-\rho_{C} g y_{C}(x, t) \mathrm{d} x}{\partial A_{n}}+\sum_{k=1}^{n_{D}} \frac{\partial\left(F_{D k} y_{C}\left(x_{D k}, t\right)\right)}{\partial A_{n}}+\sum_{k=1}^{n_{S}} \frac{\partial\left(F_{S C k} y_{C}\left(x_{S k}, t\right)\right)}{\partial A_{n}}+\frac{\partial\left(F_{C} y_{C}\left(x_{C}, t\right)\right)}{\partial A_{n}} .
$$

\section{Initialization of the Catenary}

In the initialization of the catenary, the large ratios $\alpha$ and $\beta$ are applied in the damping matrix. The strategy of the initialization process is shown in Figure 9.

The two initialization processes consist of the contact wire and the messenger wire, which can also be described in Figure 10.

According to the parameters in reference [18], the static position of the contact wire and the static forces is shown in Figure 11. The dropper force results are very close compared with the OSCAR in reference [18] as shown in Table 2 .

\section{Variation of the Main Frame}

The size parameters of the pantograph's main structure considered here are shown in Figure 12 and listed in Table 3, and several important rules need to be noticed.

4.1. Height Design. The most important height values related to the pantograph-catenary system are shown in Figure 13, where $H_{1}$ is the designed height value between the contact line and the steel rail surface. $H_{1}$ is usually $5.3 \mathrm{~m}$ in China's high-speed railway. $\mathrm{H}_{2}$ is the working height defined representing the vertical distance between the pantograph mounting plane on the top of insulators and the upper surface of contact strips. $\mathrm{H}_{3}$ is the height value decided by the size of the pantograph's main frame, which is set as a constant value of $1.6 \mathrm{~m}$ in this paper to analyze the effect of the main frame's size.

4.2. Variation Rules. The size control of the pantograph's main frame should comply with equation (30) to satisfy the designed height $\mathrm{H}_{3}$.

$$
\begin{aligned}
& L_{1} \cos \left(\theta_{10}\right)+L_{5} \cos \left(\theta_{5}+\theta_{20}\right)-L_{4} \cos \left(\theta_{40}\right)-L_{a}=0, \\
& L_{1} \sin \left(\theta_{10}\right)+L_{5} \sin \left(\theta_{5}+\theta_{20}\right)-L_{4} \sin \left(\theta_{40}\right)-L_{b}=0, \\
& L_{1} \sin \left(\theta_{10}\right)+L_{2} \sin \left(\theta_{20}\right)-H_{3}=0 .
\end{aligned}
$$

The initial position of the pantograph's main frame to keep $\mathrm{H}_{3}$ as a constant value at different size parameters is shown in Figure 14. Several conditions failed to satisfy the rules when the changing ratio is larger. $L_{1}$ failed when the change ratio is $-15 \%$, and $L_{4}$ failed when the change ratios are $10 \%$ and 15\%, shown in Figures 14(a) and 14(c).

The moments of inertia of the components $I_{i}$ changed following the size parameters, and each component is assumed to be a uniform bar.

$$
I_{i}=\frac{1}{12} m_{i} L_{i}^{2}
$$

where $I_{i}$ is the $i$ th components' moment of inertia, $L_{i}$ is the length, and $m_{i}$ is the constant parameter; $I_{i}$ will change as $L_{i}$ changes, as shown in equation (31).

4.3. Static Contact Force and Pantograph Raise Torque. When designing the pantograph-catenary system, the static contact force plays an important role and needs to be carefully considered. For all conditions simulated in this paper, the static force is set as a constant value $70 \mathrm{~N}$. Thus, the torque raising value of the pantograph will be redesigned in each size parameter condition. The force analysis diagram is shown in Figure 15.

For collector strips loaded on the upper frame,

$$
F_{\mathrm{O} 3}=F_{\text {Static }}+m_{L} g+m_{R} g \text {. }
$$

For the upper frame,

$$
\begin{aligned}
& \sum F_{y}(\text { up })=0 ; \\
& \sum F_{x}(\text { up })=0 ; \\
& \sum M_{\mathrm{O}_{2}}(\text { up })=0 .
\end{aligned}
$$

For the link,

$$
\begin{aligned}
& \sum F_{y}(\operatorname{lin})=0 ; \\
& \sum F_{x}(\operatorname{lin})=0 ; \\
& \sum M_{O_{1}}(\operatorname{lin})=0 .
\end{aligned}
$$

For the lower frame,

$$
\sum M_{\mathrm{O}_{4}}(\mathrm{lo})=0
$$

The computed raising torque values are shown in Table 4 with different parameters.

\subsection{Others Need to Be Noticed}

(1) The total mass of the pantograph's main is constant, and the target force is a constant value of $70 \mathrm{~N}$, and the changes of the torque values are due to the variation of gravity center of the pantograph caused by size changing.

(2) The aerodynamics effects are always treated as the constant value corresponding to speed, which are not considered in pantograph-catenary interaction.

(3) The catenary parameters simulated in the paper are based on EN50318:2002 [46], and the initial parameters of the pantograph are simplified based on pantograph SSS400+ [47].

(4) The effects of the vertical movement of the train body to contact quality are not considered here. 


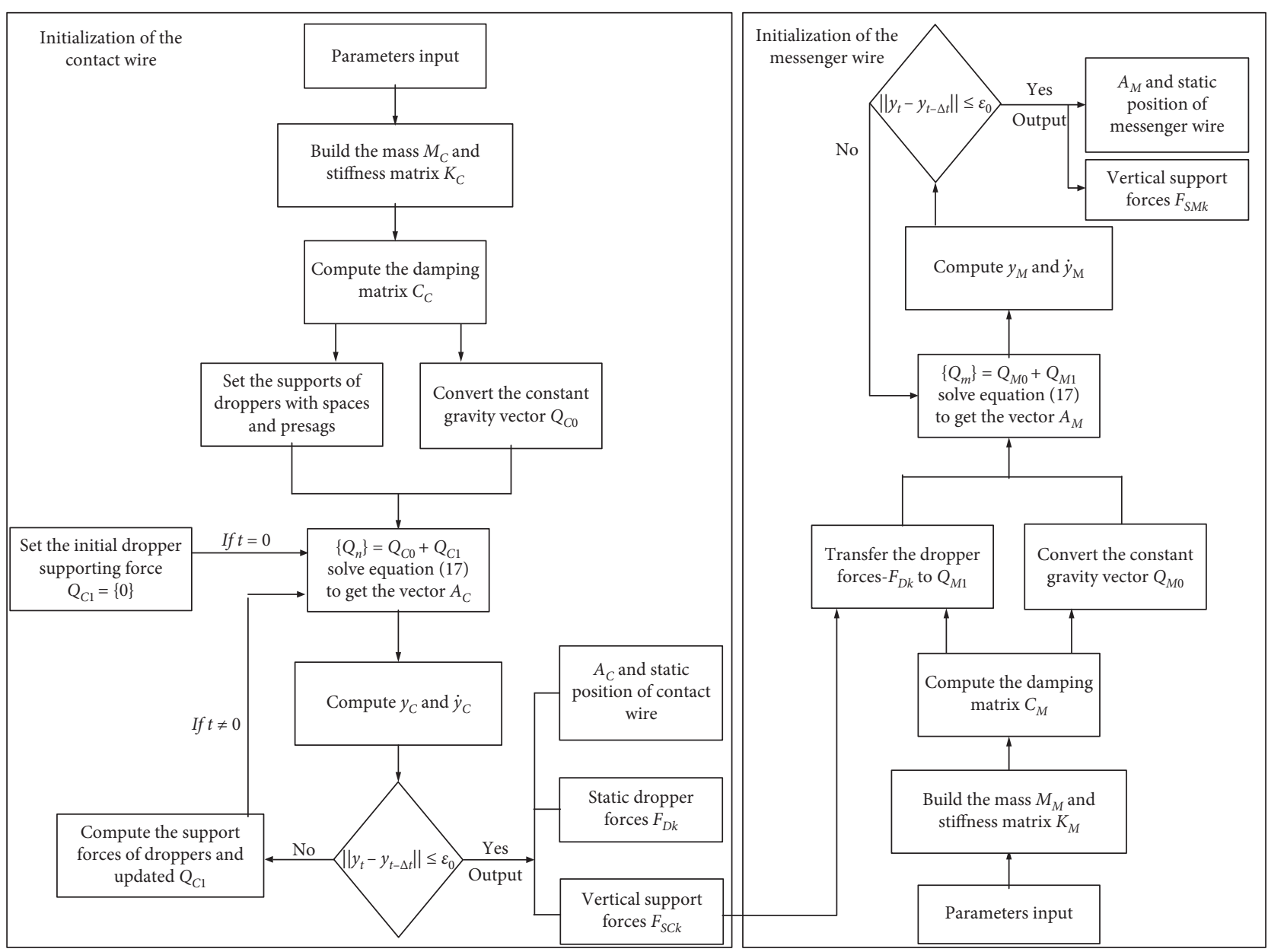

FIgURE 9: Initialization of the catenary.

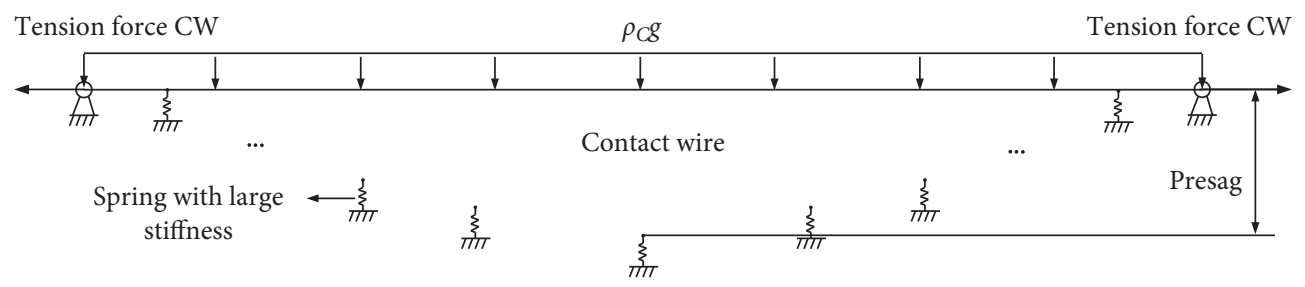

Support dropper $i$ in one span

Messenger wire

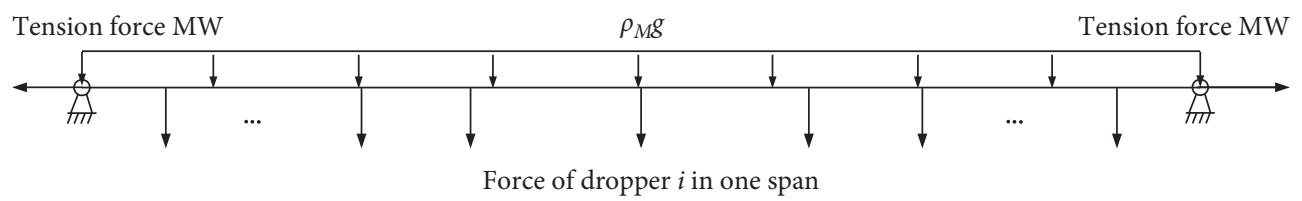

FIGURE 10: Initialization of the contact wire and the messenger wire. 


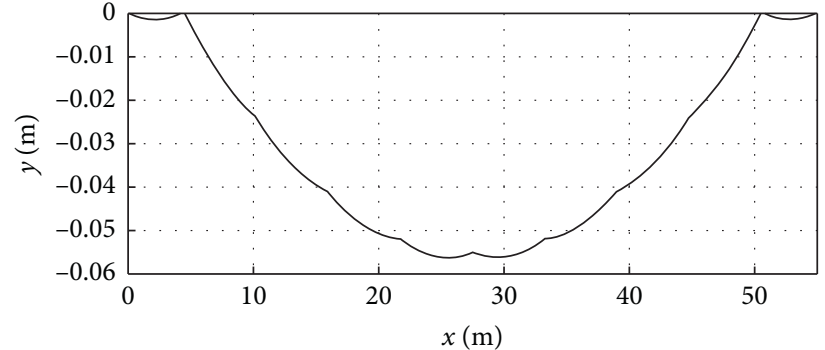

Static position of contact wire

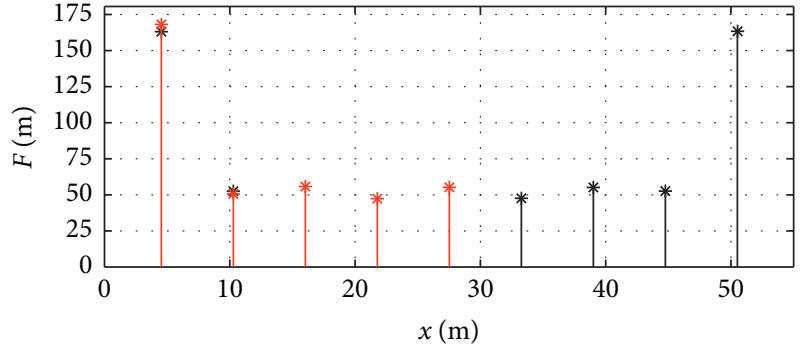

* Static dropper forces by methods * Results from OSCAR

(b)

FIGURE 11: Initialization of the contact wire and the messenger wire.

TABLE 2: Dropper forces results of the model against the OSCAR.

\begin{tabular}{lccc}
\hline Force item & OSCAR value $(\mathrm{N})$ & Model value $(\mathrm{N})$ & Relative error $(\%)$ \\
\hline Dropper 1 & 167.90 & 163.03 & -2.90 \\
Dropper 2 & 50.67 & 52.50 & 3.61 \\
Dropper 3 & 55.47 & 55.13 & -0.61 \\
Dropper 4 & 47.52 & 47.67 & 0.31 \\
Dropper 5 & 55.39 & 55.08 & -0.56 \\
\hline
\end{tabular}

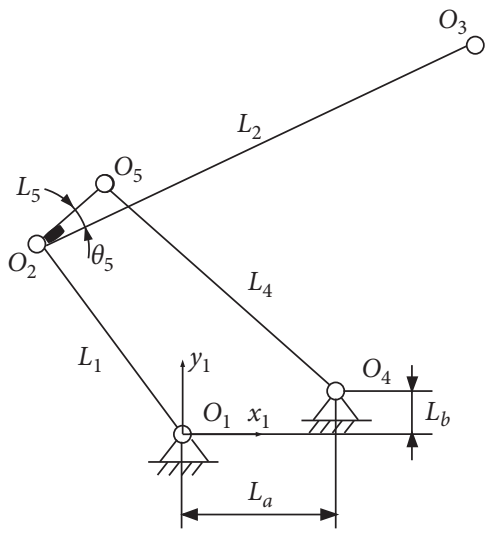

FIGURE 12: Main size parameters considered in the simulation.

TABLE 3: Initial size parameters.

\begin{tabular}{|c|c|c|c|}
\hline Items & Description & Reference value & Range \\
\hline$L_{1}$ & Length of the link & $1.18 \mathrm{~m}$ & \\
\hline$L_{2}$ & Length of the upper frame & $2.21 \mathrm{~m}$ & \\
\hline$L_{4}$ & Length of the lower frame & $1.6 \mathrm{~m}$ & \\
\hline$L_{5}$ & Length between $\mathrm{O}_{2}$ and $\mathrm{O}_{5}$ & $0.29 \mathrm{~m}$ & $1-15 \%$ to $1+15 \%$ \\
\hline$\theta_{5}$ & Angle between $L_{5}$ and $L_{2}$ & $12.83^{\circ}$ & \\
\hline$L_{a}$ & Distance between $O_{1}$ and $O_{4}$ along $x_{1}$ direction & $0.72 \mathrm{~m}$ & \\
\hline$L_{b}$ & Distance between $O_{1}$ and $O_{4}$ along $y_{1}$ direction & $0.15 \mathrm{~m}$ & \\
\hline
\end{tabular}




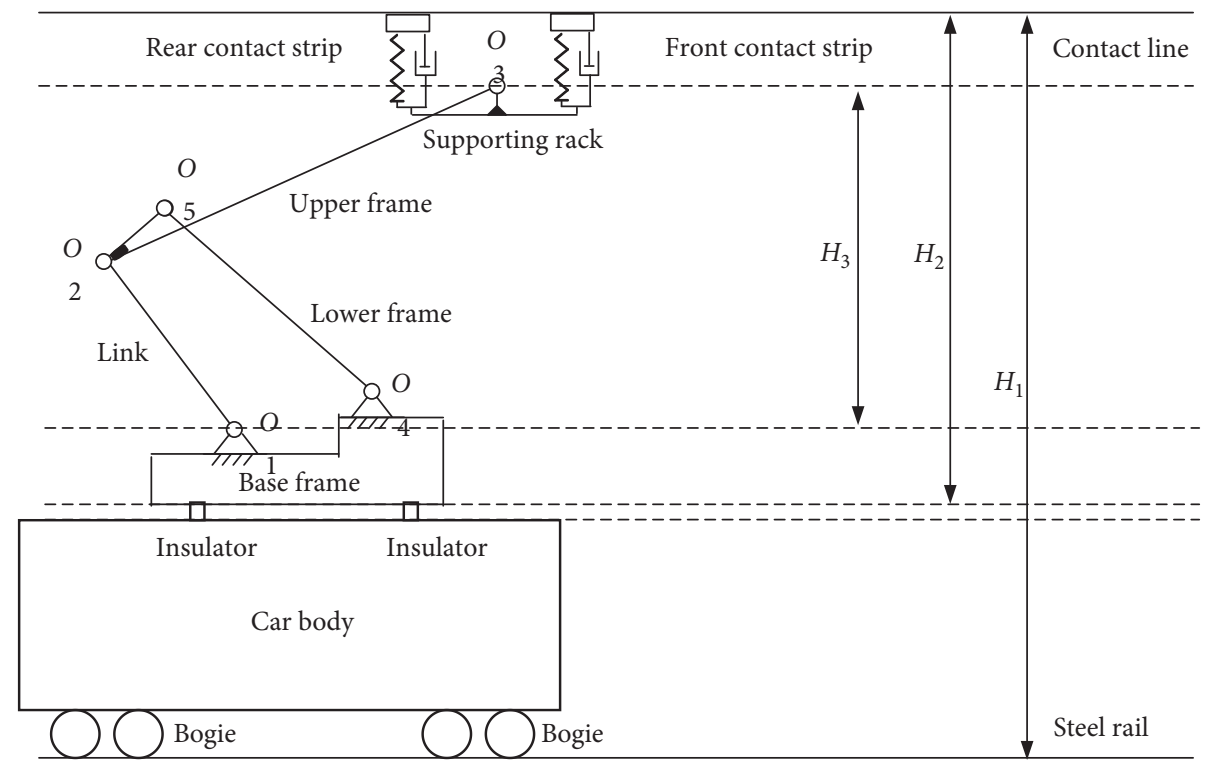

FIGURE 13: Important height values relating to the pantograph-catenary system.

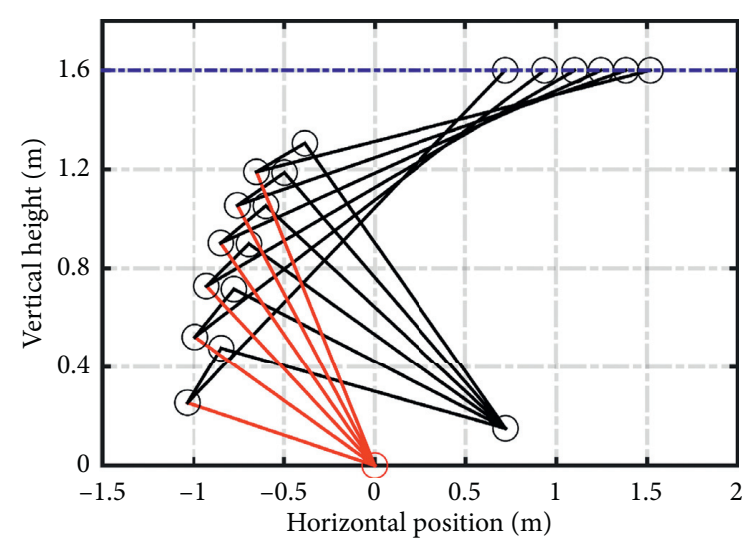

(a)

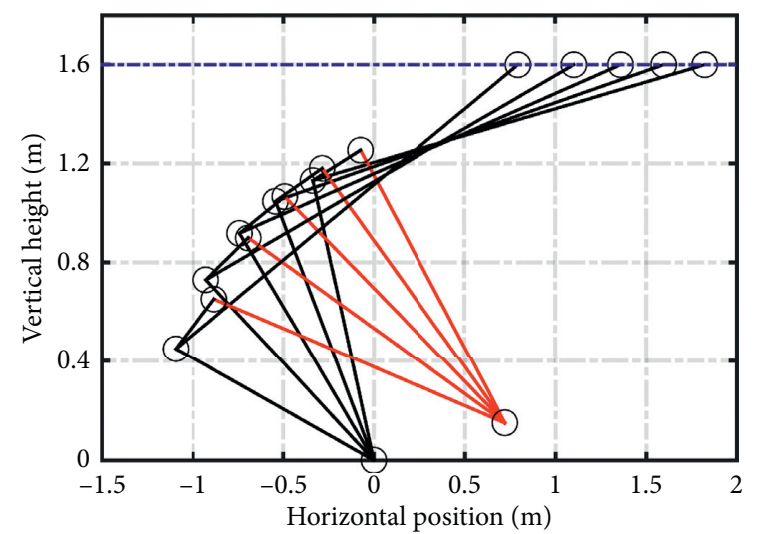

(c)

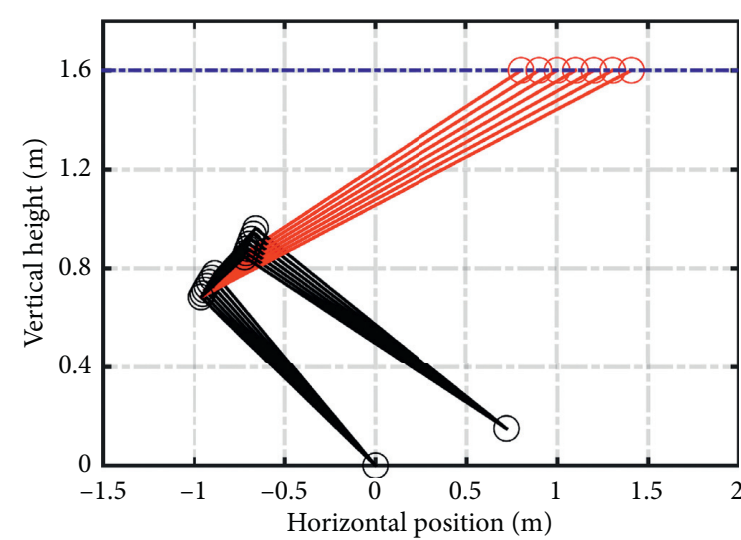

(b)

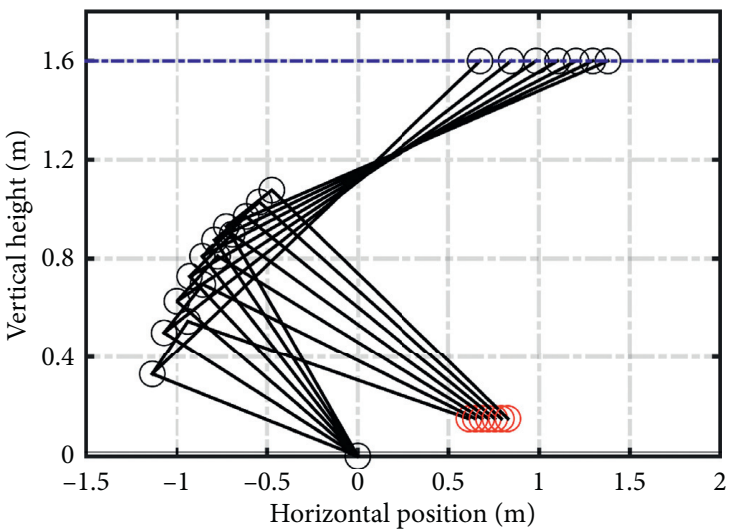

(d)

Figure 14: Continued. 


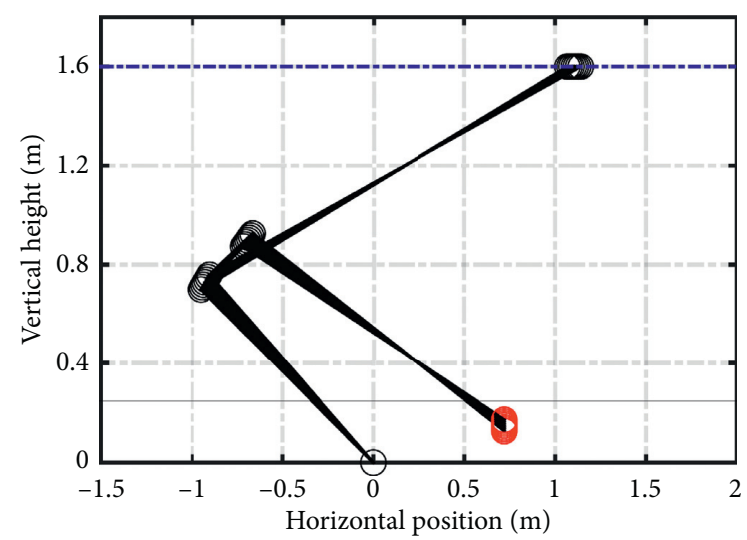

(e)

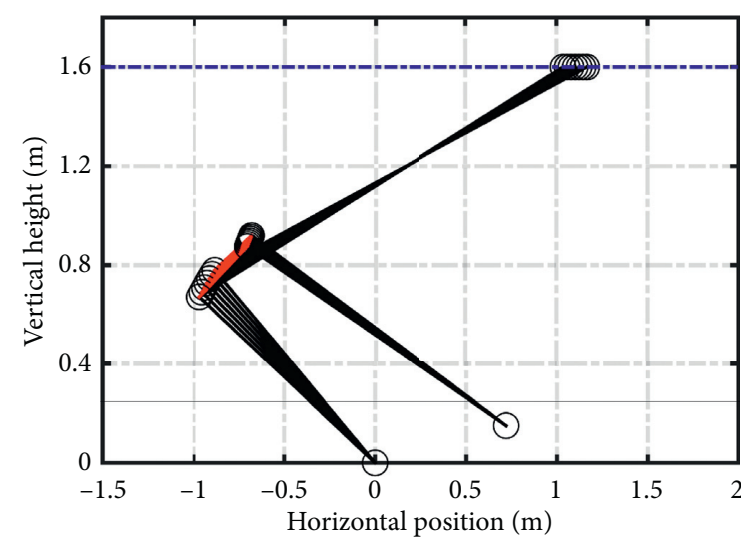

(f)

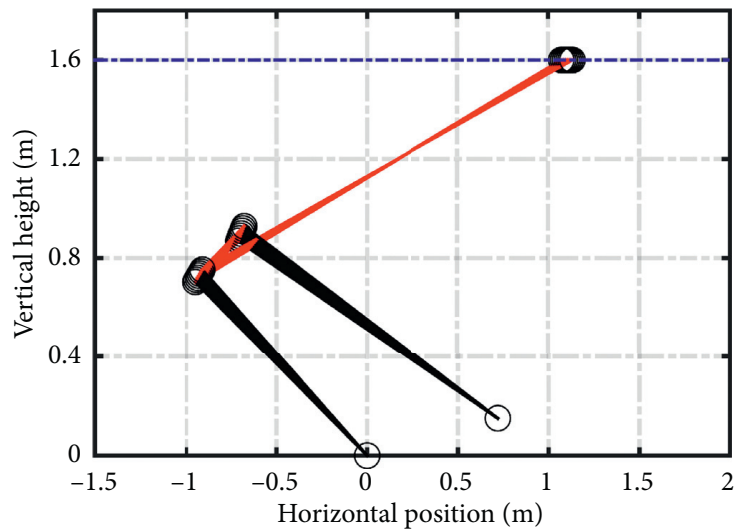

(g)

Figure 14: The initial position of the pantograph's main frame (the red lines or hinges in this figure are the related variable parameters): (a) variation of $L_{1}$ (failed at $-15 \%$ ); (b) variation of $L_{2}$; (c) variation of $L_{4}$ (failed at $10 \%$ and $15 \%$ ); (d) variation of $L_{a}$; (e) variation of $L_{b}$; (f) variation of $L_{5}$; $(\mathrm{g})$ variation of $\theta_{5}$ (the angles between two red lines).

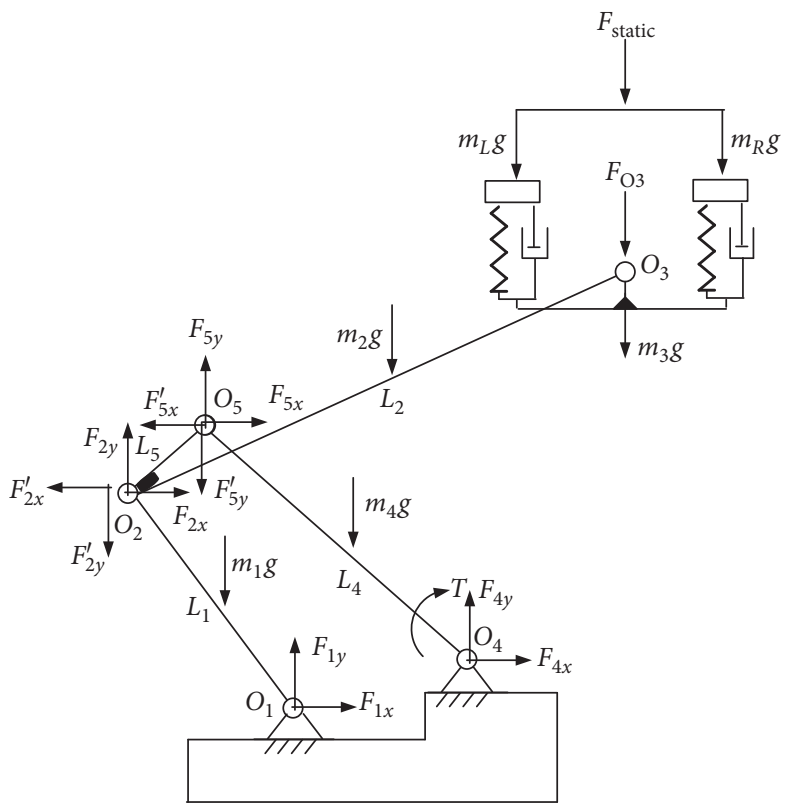

FIgURe 15: Static force analysis. 

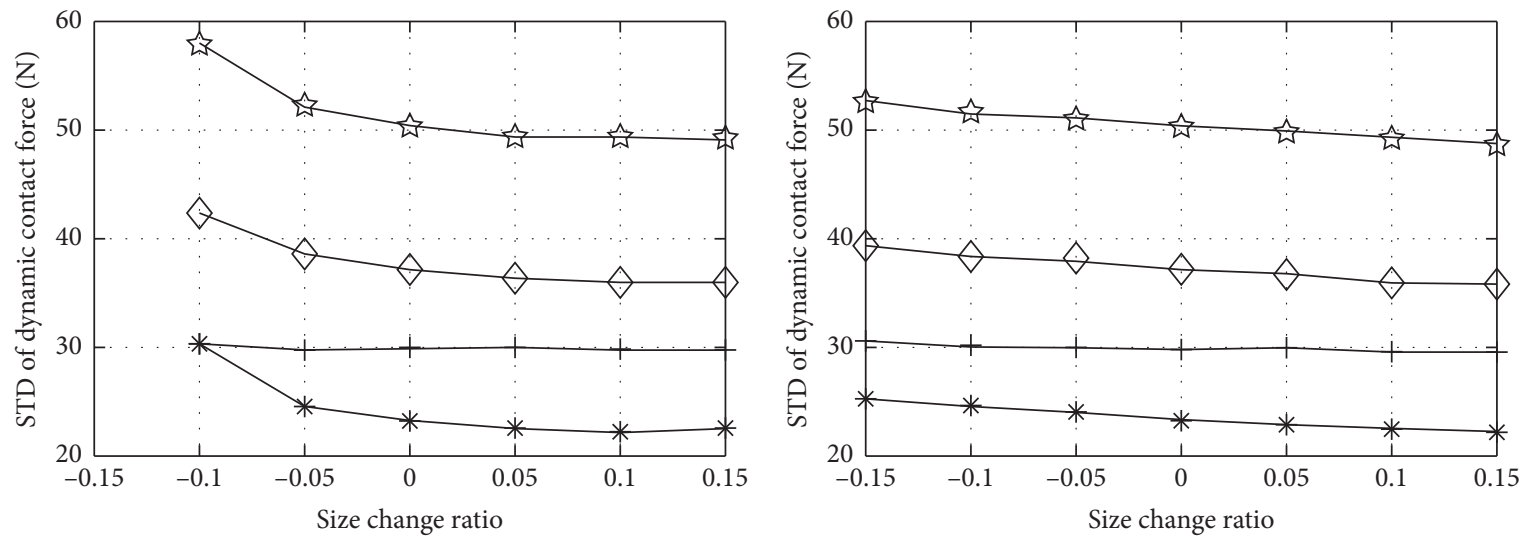

$\begin{array}{ll}* 200 \mathrm{~km} / \mathrm{h} & \succ 300 \mathrm{~km} / \mathrm{h} \\ +250 \mathrm{~km} / \mathrm{h} & \neg 350 \mathrm{~km} / \mathrm{h}\end{array}$

(a)

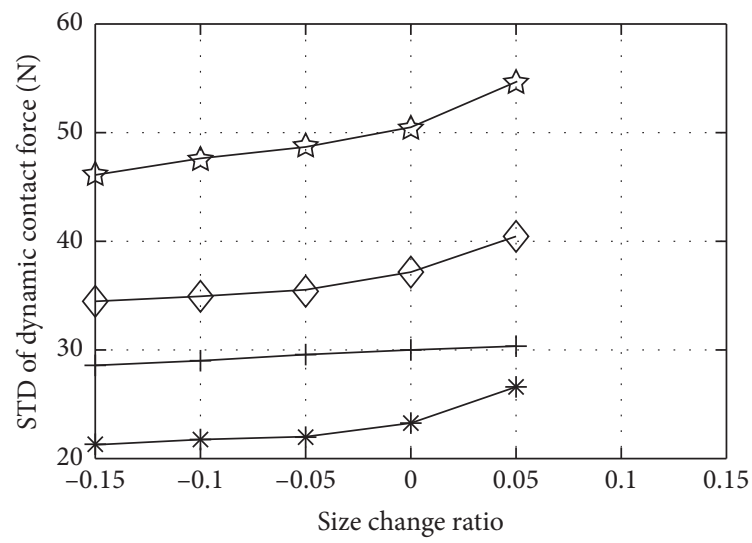

* $200 \mathrm{~km} / \mathrm{h}$

$+250 \mathrm{~km} / \mathrm{h}$

$\diamond 300 \mathrm{~km} / \mathrm{h}$

$350 \mathrm{~km} / \mathrm{h}$

(c)

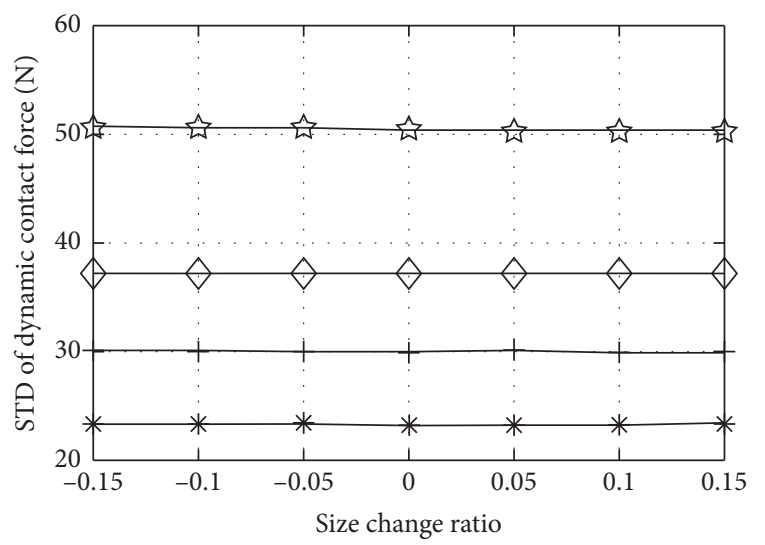

* $200 \mathrm{~km} / \mathrm{h}$

$\diamond 300 \mathrm{~km} / \mathrm{h}$

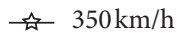

(e)

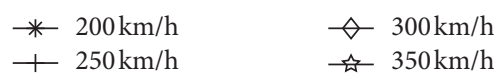

(b)

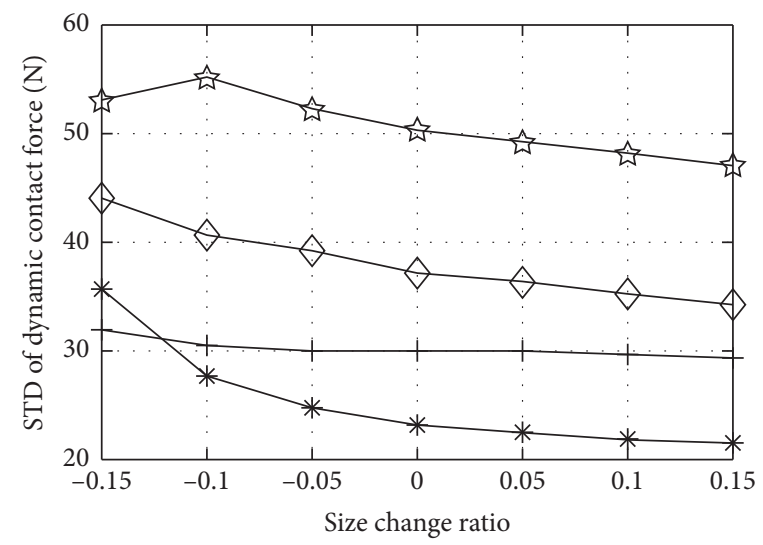

* $200 \mathrm{~km} / \mathrm{h}$

$\diamond 300 \mathrm{~km} / \mathrm{h}$

$+250 \mathrm{~km} / \mathrm{h}$

근 $350 \mathrm{~km} / \mathrm{h}$

(d)

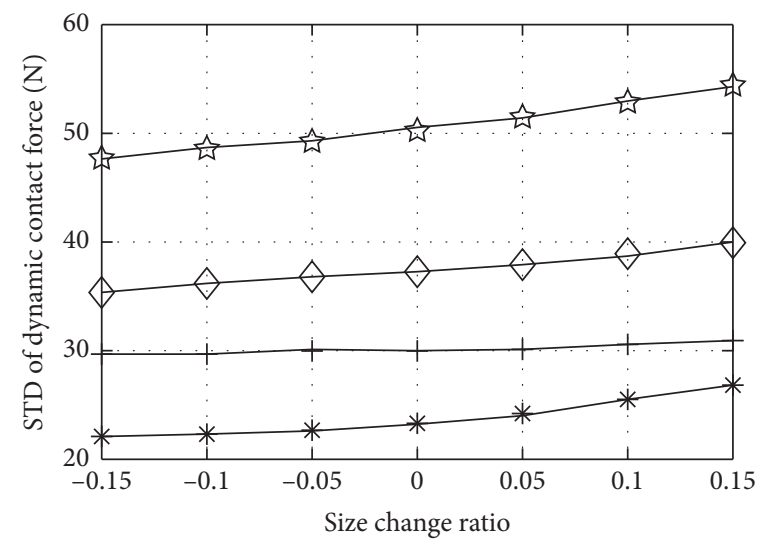

* $200 \mathrm{~km} / \mathrm{h}$

$\diamond 300 \mathrm{~km} / \mathrm{h}$

$+250 \mathrm{~km} / \mathrm{h}$

근 $350 \mathrm{~km} / \mathrm{h}$

(f)

Figure 16: Continued. 


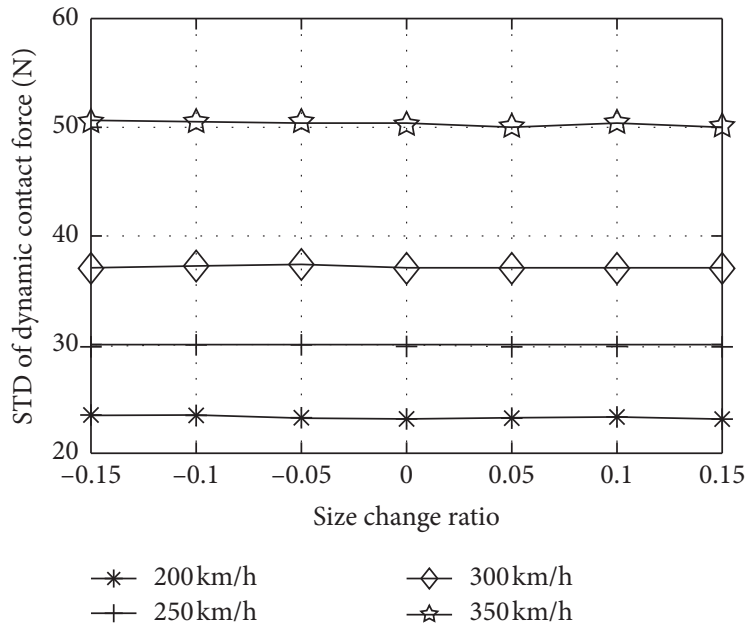

(g)

FIGURE 16: STD of the dynamic contact force: (a) variation of $L_{1}$ (failed at $-15 \%$ ); (b) variation of $L_{2}$; (c) variation of $L_{4}$ (failed at $10 \%$ and $15 \%)$; (d) variation of $L_{a}$; (e) variation of $L_{b}$; (f) variation of $L_{5}$; (g) variation of $\theta_{5}$.

TABLE 4: Torque value $T / \mathrm{Nm}$ with variable parameters.

\begin{tabular}{lccccccc}
\hline & $L_{1}$ & $L_{2}$ & $L_{4}$ & $L_{5}$ & $\theta_{5}$ & $L_{a}$ \\
\hline $1-15 \%$ & $\times$ & 990.8 & 1079.7 & 1296.2 & 1073.4 & 770.2 & 1061.1 \\
$1-10 \%$ & 778.2 & 1020.2 & 1115.5 & 1214.8 & 1074.8 & 889.4 & 1066.7 \\
$1-5 \%$ & 969.1 & 1049.2 & 1122.8 & 1142.6 & 1076.4 & 989.67 & 1072.3 \\
1 & 1078.1 & 1078.1 & 1078.1 & 1078.1 & 1078.1 & 1078.1 & 1078.1 \\
$1+5 \%$ & 1138.6 & 1106.7 & 939.4 & 1020.2 & 1079.8 & 1158.8 & 1083.9 \\
$1+10 \%$ & 1165.0 & 1135.3 & $\times$ & 968.1 & 1081.7 & 1234.7 & 1089.9 \\
$1+15 \%$ & 1164.8 & 1163.7 & $\times$ & 921.0 & 1083.7 & 1307.5 & 1095.97 \\
\hline
\end{tabular}

" $X$ " means the failure to the height rules and will not be considered in the simulation procession.

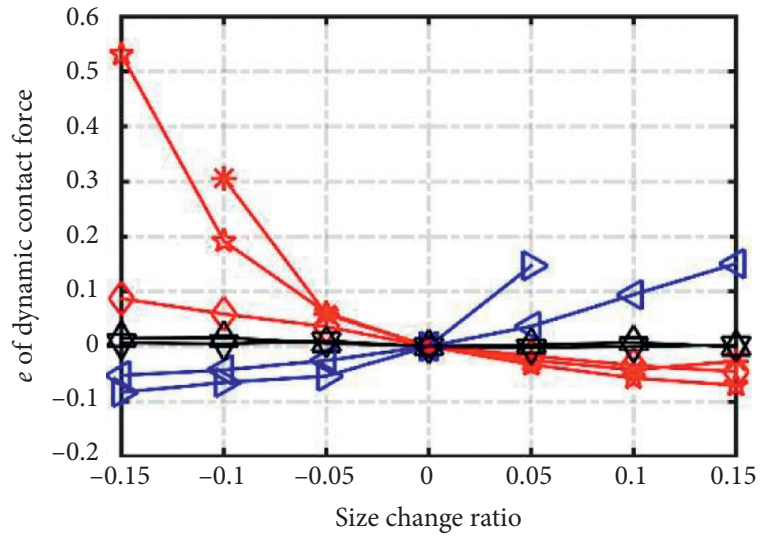

$$
\begin{array}{ll}
* L_{1} & \varangle L_{5} \\
\neg L_{2} & -L_{b} \\
\neg L_{a} & \triangle \theta_{5}
\end{array}
$$

(a)

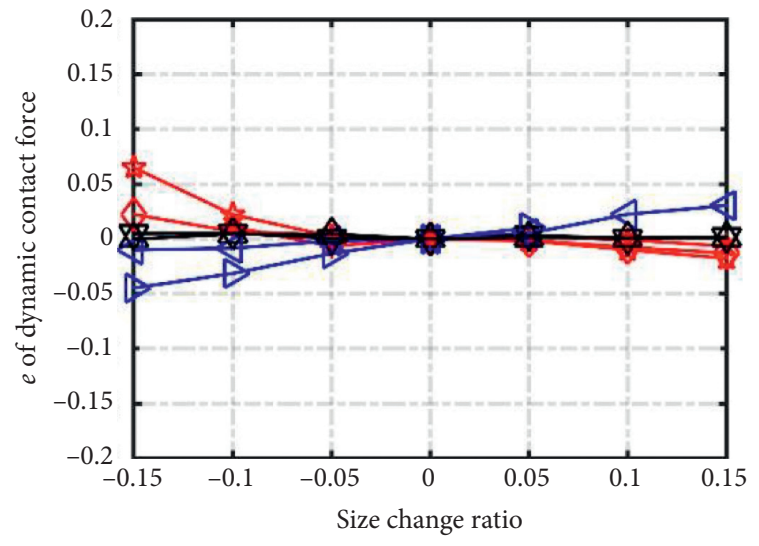

$$
\begin{array}{ll}
* L_{1} & -L_{5} \\
\diamond L_{2} & -\checkmark L_{b} \\
\neg L_{a} & \triangle \theta_{5}
\end{array}
$$

(b)

FIgURE 17: Continued. 


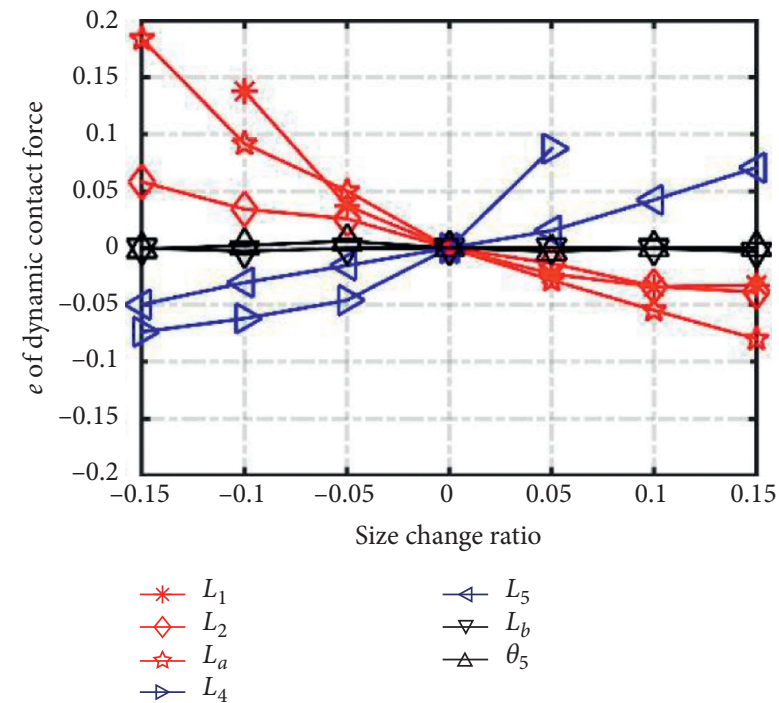

(c)

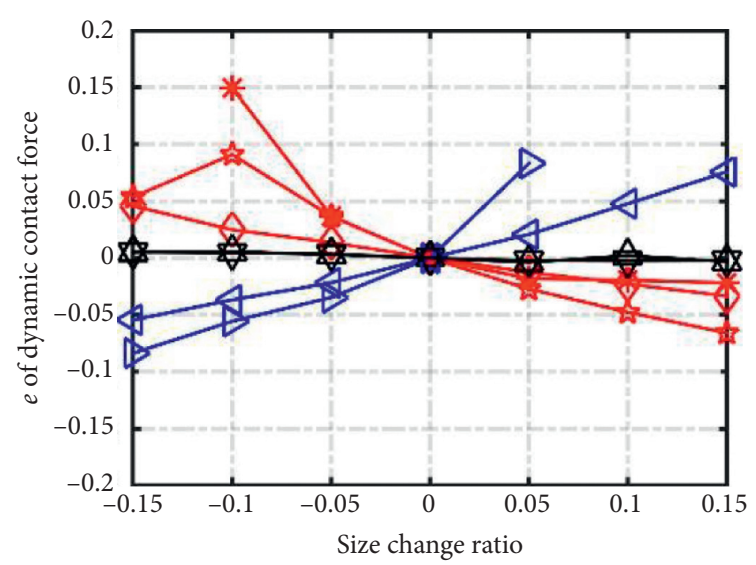

$$
\begin{aligned}
& \rightarrow L_{1} \\
& \diamond L_{2} \\
& \multimap L_{a} \\
& \rightarrow L_{4}
\end{aligned}
$$

(d)

Figure 17: Relative change rate $e$ at different speeds (basically, the red lines mean decrease, the blue lines mean increase, and the black lines mean small change): (a) $200 \mathrm{~km} / \mathrm{h}$; (b) $250 \mathrm{~km} / \mathrm{h}$; (c) $300 \mathrm{~km} / \mathrm{h}$; (d) $350 \mathrm{~km} / \mathrm{h}$.

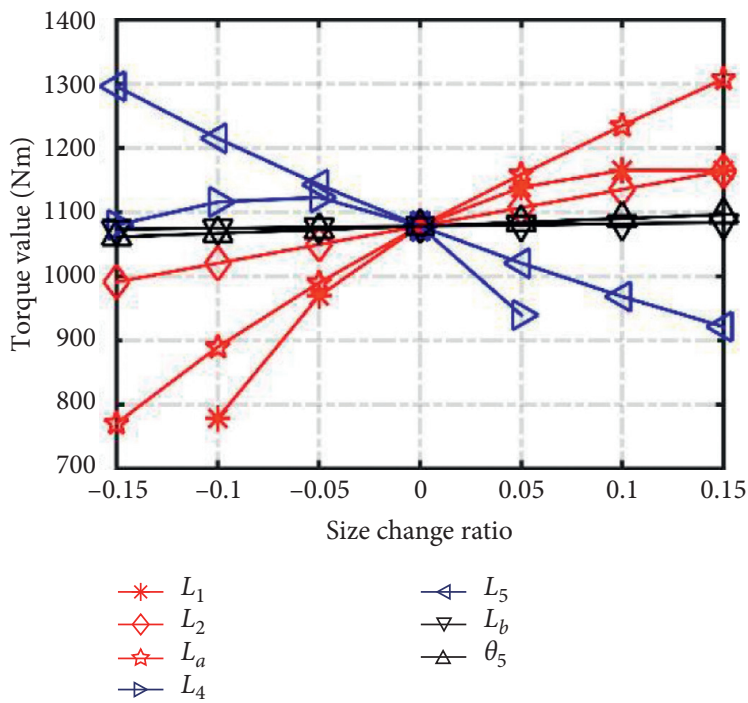

Figure 18: Torque values to meet the static contact force $70 \mathrm{~N}$ and the designed height $1.6 \mathrm{~m}$.

\section{Simulation Results and Discussion}

The STDs of the dynamic contact force simulated related to varying size values at different running speeds from $200 \mathrm{~km} /$ $\mathrm{h}$ to $350 \mathrm{~km} / \mathrm{h}$ are shown in Figure 16 .

Three basic laws can be concluded in Figure 16.

(1) The STDs of dynamic contact force decrease as the size values of $L_{1}, L_{2}$, and $L_{a}$ increase

(2) The STDs of dynamic contact force increase as the size values of $L_{4}$ and $L_{5}$ increase
(3) The size values of $L_{b}$ and $\theta_{5}$ are not sensitive to the contact quality

To evaluate the effect of variation on STD, the relative rate of change $e$ is used:

$$
e=\frac{\sigma-\sigma_{0}}{\sigma_{0}},
$$

where $\sigma_{0}$ is the STD for the initial parameters.

It is more obvious in Figure 17 that the length of the link $\left(L_{1}\right)$, the upper frame $\left(L_{2}\right)$, and the size value along $x$ - 
direction between $O_{1}$ and $O_{4}\left(L_{a}\right)$ are sensitive to the contact quality, which will improve current collection quality at the larger size values. The lower frame $\left(L_{5}\right)$ and the distance between $\mathrm{O}_{2}$ and $\mathrm{O}_{5}$ are also sensitive to contact quality, which will improve current collection quality at the smaller size values. The vertical distance between $O_{1}$ and $O_{4}\left(L_{b}\right)$ and the angle between $L_{2}$ and $L_{5}\left(\theta_{5}\right)$ are not sensitive enough to the contact quality compared with other size parameters.

The torque value applied to the lower frame changes with variable size values under the same target designed operation height and static contact force. The changing law of the torque value is in opposition as to the contact quality, shown in Figures 17 and 18. When the size values of $L_{1}, L_{2}$, and $L_{a}$ become lager, the raising torque values will increase and the STDs will decrease, indicating that the contact quality will improve when the torque value increases while the designed height and vertical static contact force are constant.

\section{Conclusion}

This paper established the dynamic mathematic model of pantograph-catenary systems and analyzed the variation of the pantograph's main frame including the link, the upper frame, the lower frame, and the hinge positions. Two important conclusions can be given as follows:

(1) Most geometric values of the pantograph's main frame are sensitive to contact quality and show different influence laws, which need to be carefully considered when designing a pantograph to suit a known catenary

(2) Larger pantograph-raising torque value is effective to improve the pantograph-catenary interaction when the static force value and the operation height are determined in advance

The work here is important for the structure design and parameters optimization of the pantograph; however, more research works remain needed to be done consisting of how the aerodynamic force acts on the pantograph which is different from that acts on a mass-spring model, whether the flexibility of the upper frame needs to be concerned in parameters optimization of the pantograph, and how the mass distribution of the pantograph's main frame influences the contact quality.

\section{Data Availability}

The data cannot be available at this moment, as this is used in an ongoing study.

\section{Conflicts of Interest}

The authors declare that they have no conflicts of interest.

\section{References}

[1] G. Poetsch, J. Evans, R. Meisinger et al., "Pantograph/catenary dynamics and control," Vehicle System Dynamics, vol. 28, no. 2-3, pp. 159-195, 1997.
[2] A. Collina and S. Bruni, "Numerical simulation of pantograph-overhead equipment interaction," Vehicle System Dynamics, vol. 38, no. 4, pp. 261-291, 2002.

[3] S. H. Kia, F. Bartolini, A. Mpanda-Mabwe, and R. Ceschi, "Pantograph-catenary interaction model comparison," in IECON 2010 - 36th Annual Conference on IEEE Industrial Electronics Society, pp. 1584-1589, Glendale, AZ, USA, November 2010.

[4] S. Bruni, G. Bucca, M. Carnevale, A. Collina, and A. Facchinetti, "Pantograph-catenary interaction: recent achievements and future research challenges," International Journal of Reality Therapy, vol. 6, no. 2, pp. 57-82, 2018.

[5] L. Drugge, T. Larsson, and A. Stensson, "Modelling and simulation of catenary-pantograph interaction," Vehicle System Dynamics, vol. 33, no. 1, pp. 490-501, 1999.

[6] J. R. Jimenez-Octavio, M. Such, A. Carnicero, and O. LopezGarcia, "Validation of simulation approaches for catenarypantograph dynamics," in Proceedings of the 9th International Conference on Computational Structures Technology, Athens, Greece, January 2009.

[7] K. Petri and J. Wallaschek, "Analytical models for the dynamics of catenary-pantograph systems," in Proceedings of the ICIAM 95, ZAMM, Sonderheft Applied Science and Mechanics, Paderbon, Germany, 1996.

[8] J. P. Massat, J. P. Laine, and A. Bobillot, "Pantograph-catenary dynamics simulation," Vehicle System Dynamics, vol. 44, no. 1, pp. 551-559, 2006.

[9] M. Schaub and B. Simeon, "Pantograph-catenary dynamics: an analysis of models and simulation techniques," Mathematical and Computer Modelling of Dynamical Systems, vol. 7, no. 2, pp. 225-238, 2001.

[10] A. Bobillot, J.-P. Massat, and J.-P. Mentel, "Design of pantograph-catenary systems by simulation," in Proceedings of the 10th International Conference on Computational Structures Technology, Valencia, Spain, May 2010.

[11] J. Ambrósio, F. Rauter, J. Pombo, and M. S. Pereira, “A flexible multibody pantograph model for the analysis of the catenarypantograph contact," in Computational Methods in Applied SciencesSpringer, Berlin, Germany, 2011.

[12] T. X. Wu and M. J. Brennan, "Basic analytical study of pantograph-catenary system dynamics," Vehicle System Dynamics, vol. 30, no. 6, pp. 443-456, 1998.

[13] Z. Jian, L. Wenzheng, Y. Meili, and Y. Zhongping, "Simulation analysis of offline characteristics between pantograph and catenary," IET Electrical Systems in Transportation, vol. 7, no. 3, pp. 252-257, 2017.

[14] S. Gregori, M. Tur, E. Nadal, J. V. Aguado, F. J. Fuenmayor, and F. Chinesta, "Fast simulation of the pantograph-catenary dynamic interaction," Finite Elements in Analysis and Design, vol. 129, pp. 1-13, 2017.

[15] S. Kulkarni, C. M. Pappalardo, and A. A. Shabana, "Pantograph/catenary contact formulations," Journal of Vibration and Acoustics, vol. 139, no. 1, 2016.

[16] P. Zdziebko and T. Uhl, "Simulation methods for pantographcatenary dynamic interaction," in project Mechatroniczne Zagadnienia WybraneAGH University of Science and Technology, Kraków, Poland, 2016.

[17] P. Zdziebko and T. Uhl, "Modelling and simulating the pantograph-catenary interaction," in Project Mechatroniczne Zagadnienia WybraneAGH University of Science and Technology, Kraków, Poland, 2015.

[18] S. Bruni, J. Ambrosio, A. Carnicero et al., "The results of the pantograph-catenary interaction benchmark," Vehicle System Dynamics, vol. 53, no. 3, pp. 412-435, 2015. 
[19] G. Mei, J. Wang, C. Zhao et al., "Research on aerodynamic experiment and dynamic performance of new developed V500 pantograph at $400 \mathrm{~km} / \mathrm{h}$ or higher," in Proceedings of the Dynamic Vehicle Roads Tracks-24th Symposium International Association Vehicle System Dynamics IAVSD, Graz, Austria, April 2016.

[20] R. Li, W. Zhang, Z. Ning, B. Liu, D. Zou, and W. Liu, "Influence of a high-speed train passing through a tunnel on pantograph aerodynamics and pantograph-catenary interaction," Proceedings of the Institution of Mechanical Engineers Part F: Journal of Rail and Rapid Transit, vol. 231, no. 2, pp. 198-210, 2017.

[21] M. Bocciolone, F. Resta, D. Rocchi, A. Tosi, and A. Collina, "Pantograph aerodynamic effects on the pantograph-catenary interaction," Vehicle System Dynamics, vol. 44, no. 1, pp. 560-570, 2006.

[22] J. Pombo, J. Ambrósio, M. Pereira, F. Rauter, A. Collina, and A. Facchinetti, "Influence of the aerodynamic forces on the pantograph-catenary system for high-speed trains," Vehicle System Dynamics, vol. 47, no. 11, pp. 1327-1347, 2009.

[23] A. Carnicero, J. R. Jimenez-Octavio, C. Sanchez-Rebollo, A. Ramos, and M. Such, "Influence of track irregularities in the catenary-pantograph dynamic interaction," Journal of Computational and Nonlinear Dynamics, vol. 7, no. 4, 2012.

[24] W. Zhang, G. Mei, and J. Zeng, "A study of pantograph/ catenary system dynamics with influence of $\mathrm{p}$ and irregularity of contact wire," Vehicle System Dynamics, vol. 37, no. 1, pp. 593-604, 2002.

[25] Y. Qin, Y. Zhang, X.-q. Cheng, L.-m. Jia, and Z.-y. Xing, "An analysis method for correlation between catenary irregularities and pantograph-catenary contact force," Journal of Central South University, vol. 21, no. 8, pp. 3353-3360, 2014.

[26] M. T. Ko, M. Yokoyama, Y. Yamashita, S. Kobayashi, and T. Usuda, "Contact force control of an active pantograph for high speed trains," Journal of Physics: Conference Series, vol. 744, Article ID 012151, 2016.

[27] B. Allotta, L. Pugi, A. Rindi, and M. Rinchi, "Active contact force control of pantograph," in Computational Railway ViiWIT Press, Billerica, MA, USA, 2000.

[28] J. Wang, "Active control of contact force for a pantographcatenary system," Shock and Vibration, vol. 2016, Article ID 2735297, 7 pages, 2016.

[29] Y. Song, H. Ouyang, Z. Liu, G. Mei, H. Wang, and X. Lu, "Active control of contact force for high-speed railway pantograph-catenary based on multi-body pantograph model," Mechanism and Machine Theory, vol. 115, pp. 35-59, 2017.

[30] C. Sanchez-Rebollo, J. R. Jimenez-Octavio, and A. Carnicero, "Active control strategy on a catenary-pantograph validated model," Vehicle System Dynamics, vol. 51, no. 4, pp. 554-569, 2013.

[31] F. Resta, A. Collina, and F. Fossati, "Actively controlled pantograph: an application," in Proceedings of the 2001 IEEE/ ASME International Conference on Advanced Intelligent Mechatronics, Como, Italy, July 2002.

[32] T.-C. Lin, J.-L. Yeh, C.-H. Kuo, Y.-C. Lin, and V. E. Balas, "Adaptive fuzzy sliding mode active vibration control for rail vehicle pantograph," in Proceedings of the 2016 IEEE International Conference on Fuzzy Systems (FUZZ-IEEE), pp. 373-379, Vancouver, Canada, July 2016.

[33] T.-J. Park, C.-S. Han, and J.-H. Jang, "Dynamic sensitivity analysis for the pantograph of a high-speed rail vehicle,"
Journal of Sound and Vibration, vol. 266, no. 2, pp. 235-260, 2003.

[34] J.-W. Kim, H.-C. Chae, B.-S. Park, S.-Y. Lee, C.-S. Han, and J.-H. Jang, "State sensitivity analysis of the pantograph system for a high-speed rail vehicle considering span length and static uplift force," Journal of Sound and Vibration, vol. 303, no. 3-5, pp. 405-427, 2007.

[35] N. Zhou and W. Zhang, "Investigation on dynamic performance and parameter optimization design of pantograph and catenary system," Finite Elements in Analysis and Design, vol. 47, no. 3, pp. 288-295, 2011.

[36] J. Ambrósio, J. Pombo, and M. Pereira, "Optimization of high-speed railway pantographs for improving pantographcatenary contact," Theoretical and Applied Mechanics Letters, vol. 3, no. 1, Article ID 013006, 2013.

[37] J. Pombo and J. Ambrósio, "Influence of pantograph suspension characteristics on the contact quality with the catenary for high speed trains," Computers \& Structures, vol. 110111, pp. 32-42, 2012.

[38] J.-H. Lee, Y.-G. Kim, J.-S. Paik, and T.-W. Park, "Performance evaluation and design optimization using differential evolutionary algorithm of the pantograph for the high-speed train," Journal of Mechanical Science and Technology, vol. 26, no. 10, pp. 3253-3260, 2012.

[39] J.-P. Massat, C. Laurent, J.-P. Bianchi, and E. Balmès, "Pantograph catenary dynamic optimisation based on advanced multibody and finite element co-simulation tools," Vehicle System Dynamics, vol. 52, no. 1, pp. 338-354, 2014.

[40] R. E. Roberson and J. Wittenburg, "A dynamical formalism for an arbitrary number of interconnected rigid bodies, with reference to the problem of satellite attitude control," in Proceedings of the International Federation of Automatic Control, London, UK, June 1966.

[41] J. Wang, G. Mei, R. Li, D. Zou, N. Zhou, and R. Li, "Dynamic load research of key components of pantograph in pantograph-catenary interaction," Tiedao Xuebao/Journal China Railway Society, vol. 40, pp. 68-75, 2018.

[42] J. Wang, G. Mei, and W. Zhang, Sensitivity Analysis Of Flexible Upper Frame Of Pantograph With A Novel Simplified Method, Springer, Berlin, Germany, 2020.

[43] J. Wang, Study in Theory and Application of Pantograph Nonlinear Dynamics ChineseSouthwest Jiaotong University, Chengdu, China, 2016.

[44] Y. Liu, J. Hong, and H. Yang, Dynamics of Multi-Rigid Body System ChineseHigher Education Press, Beijing, China, 1989.

[45] D. O. Connor, Modeling and Simulation Of PantographCatenary Systems, Massachusetts Institute of Technology, Cambridge, MA, USA, 1984.

[46] BSEN 50318, Railway Applications - Current Collection Systems - Validation of Simulation of the Dynamic Interaction between Pantograph and Overhead Contact Line, BSI, London, UK, 2002.

[47] Z. Liu, H. Wang, R. Dollevoet, Y. Song, A. Nunez, and J. Zhang, "Ensemble EMD-based automatic extraction of the catenary structure wavelength from the pantograph-catenary contact force," IEEE Transactions on Instrumentation and Measurement, vol. 65, no. 10, pp. 2272-2283, 2016. 